\title{
POST-THYMECTOMY ORGAN-SPECIFIC AUTOIMMUNITY: ENHANCEMENT BY CYCLOSPORINE A AND INHIBITION BY IL-2
}

\author{
J. BARTHELOW CLASSEN and ETHAN M. SHEVACH \\ Laboratory of Immunology, National Institute of Allergy and Infecrious Diseases, National Institutes of Health, Bethesda, MD, USA
}

(Received September 29, 1992; in final form February 5, 1993)

\begin{abstract}
It has previously been shown that the administration of cyclosporine A to newborn mice results in the development of autoimmunity later in life. It has been proposed that the neonatal administration of cyclosporine $A$ results in altered thymic selection or inhibition of the development of suppressor cells. In the present study, treatment of day 3 thymectomized $\mathrm{C} 3 \mathrm{H} / \mathrm{HeN}$ mice with cyclosporine $\mathrm{A}(20 \mathrm{mg} / \mathrm{kg} / \mathrm{day})$ for $9 \mathrm{~d}$ post surgery increased the prevalence of antigastric autoantibodies. In contrast, the administration of IL-2 (300-600 Units/g/day) for 7 days after thymectomy inhibited the development of antigastric antibodies. We hypothesize that CsA may act by causing transient lymphokine abnormalities in the extrathymic environment during the first few weeks of life which lead to the development of antigastric antibodies. In contrast to the inhibition of development of antigastric antibodies, the administration of a similar course of IL-2 produced only a transient suppression of diabetes in NOD mice. These results and other data suggest that diabetes in NOD mice is probably due to a different immunologic defect.
\end{abstract}

KEY WORDS: Gastritis, diabetes, IL-2, thymectomy, cyclosporine A.

\section{INTRODUCTION}

Two animal models have been described in which interruption of $\mathrm{T}$ cell development in the perinatal period results in the induction of organ-specific autoimmune disease. Thymectomy (Tx) of mice on day 24 of life resulted in the development of autoimmune diseases such as oophoritis, gastritis, and thyroiditis ${ }^{1.2}$. Similarly, Sakaguchi and Sakaguchi ${ }^{3}$ were able to induce autoimmune gastritis in mice by injecting them with the immunosuppressive drug, cyclosporine A $(\mathrm{CsA})^{4}$, during the first week of life. Although it has been postulated that the autoimmune diseases produced by Tx or CsA administration early in life may be secondary to the presence of "forbidden clones" which have escaped deletion in the thymus or to the absence of regulated $T$ cells needed to suppress autoreactive $T$ cells, the precise role of the $T$ lymphocyte in the pathogenesis of autoimmune disease in these models remains poorly defined.

In this report, we have induced transient alterations in the extrathymic environment of the developing immune system to help discern the cause of autoimmunity in certain animal models. We hypothesize that transient abnormalities, possibly extrathymic lymphokine deficiencies during the first 2 wk of life, could cause autoimmunity to develop later in the life of ani-

Address correspondence to: Dr E.M. Shevach, Laboratory of Immunology, NIAID, National Institutes of Health, Blg. 10, Rm 11N315, Bethesda, Maryland 20892, USA. mals. $\mathrm{C} 3 \mathrm{H}$ and NOD mice thymectomized on day 3 or 4 of life were treated with CsA and different immune modulators and the effect of these agents on the development of autoantibodies was studied. We demonstrate for the first time that the treatment of a thymectomized animal with CsA enhances the development of autoantibodies. The results give insight into possible causes of autoimmunity and may lead to the development of new approaches to modulate autoimmunity.

\section{MATERIAL AND METHODS}

\section{Animals}

$\mathrm{C} 3 \mathrm{H} / \mathrm{HeN}$ mice were obtained from the Small Animals Section, Veterinary Resources Program, NIH; NOD mice were purchased from Taconic, Germantown, NY. All animals were housed in microisolator cages and fed ad libitum.

$T x$

$\mathrm{C} 3 \mathrm{H} / \mathrm{HeN}$ and NOD mice were thymectomized between days 3 and 4 of life. The method of Sjodin et al. ${ }^{5}$ was used. Mice were anesthetized with Methoxyflurane (Pitman-Moore, Washington Crossing, New Jersey), placed on a dissecting board, and the neck cleansed with a swab saturated in alcohol. A midline longitudinal incision was made in the neck, the maxil- 
lary gland moved anteriorly, and the sternohyoid muscles separated. An incision was then made in the midline of the sternum bisecting the first four ribs. The thymus was exposed by separating the sternal halves and the thymus was aspirated using a glass pasteur pipet attached to a vacuum source. The skin was closed with 3 or 4 sutures. Sham Tx animals were made by performing the same surgical procedures except that the thymus was not aspirated and the skin incision was closed with the thymus still intact. Animals that failed to wake up immediately after surgery were caged separately from their mothers and exposed to a heat lamp to prevent hypothermia.

\section{Immune modulators}

All agents were diluted in approximately $0.05 \mathrm{ml}$ of PBS (Biofluids, Rockville, MD) and injected intraperitoneally within $24 \mathrm{~h}$ after Tx or on day 4 of life. The following immune modulators were used: CsA (Sandoz, New Jersey), human rIL2 (Hoffman La Riche, Nutley, NJ), murine IFN $\gamma$ (Amgen, Thousand Oaks, CA), normal hamster IgG (Jackson Immunoresearch, West Grove, PA), and anti-CD3 (mAb 2C11, Leo et al. $\left.{ }^{6}\right)$ purified from ascites on a protein $\mathrm{A}$ column (Beckman, Fullerton, CA).

\section{ELISA}

An enzyme-linked immunosorbent assay (ELISA) to determine the presence of autoantibodies to gastric antigen was performed as previously described ${ }^{3,7}$. Plates were read on a MicroFLUOR Reader (Dynatech, Chantilly, VA) which has a $365 \mathrm{~nm}$ broadband filter blocking the excitation beam along with both a $450 \mathrm{~nm}$ narrowband interference filter and a $400 \mathrm{~nm}$ UV blocking filter which alter the emission beam. Mouse serum was tested for antibodies at a dilution of 1:80. A standard serum was plated in triplicate in each plate and the average reading of the 3 was subtracted from the readings of the other wells in order to standardize variability from plate to plate. Diluted sera with an average reading of 200 above the standard were scored as positive. The numbers of positive sera in each treatment group were compared to determine if treatment had an effect.

\section{Blood glucose}

Blood glucose was determined by removing a few drops of tail blood from non-fasting mice which were 3 months old or older and smearing the blood on a glucose sensitive Chemstrip (Boehringer Mannheim, Indianapolis, IN). Blood glucose levels above $300 \mathrm{mg} / \mathrm{dl}$ were scored as positive.

\section{RESULTS}

\section{Administration of CsA post Tx enhances autoantibody} production

In order to determine if CsA exerted an effect on the extrathymic development of the immune system, we studied the development of autoantibodies in $\mathrm{C} 3 \mathrm{H} / \mathrm{HeN}$ mice which were thymectomized 3 to $4 \mathrm{~d}$ after birth. Approximately $50 \%$ of the thymectomized animals developed antigastric autoantibodies by 20 wk of age (Table 1; Figure 1), while antigastric antibodies were not detected in the control animals. When CsA (20 mg/kg/day) was administered for $9 \mathrm{~d}$

Table 1 Effect of immune manipulation on the production of antibodies to gastric antigen

\begin{tabular}{lrrr}
\hline Treatment & + /Total & $\%$ & $P$ value \\
\hline A. & & & \\
No Tx & $0 / 30$ & $0 \%$ & \\
Day 3 Tx & $22 / 50$ & $44 \%$ & \\
Day 3 Tx & $24 / 48$ & $50 \%$ & \\
Tx+CSA & $30 / 39$ & $77 \%$ & 0.0049 \\
Tx+IL-2* & $7 / 36$ & $19 \%$ & \\
Tx+IL-2 & $10 / 35$ & $29 \%$ & 0.0274 \\
Tx+IFN $4+$ IL-2* & $27 / 32$ & $84 \%$ & 0.0010 \\
B. & & & \\
Tx+Hamster IgG & $12 / 31$ & $39 \%$ & \\
Tx+Anti-CD3 & $23 / 27$ & $85 \%$ & 0.0004 \\
\hline
\end{tabular}

$\mathrm{C} 3 \mathrm{H} / \mathrm{HeN}$ mice were thymectomized except where otherwise indicated and treated as shown. Antigastric antigen antibody titers were determined at $11-12^{*}$ or $20 \mathrm{wk}$ of age. Statistics were performed by calculating $z$ yalues using a test for difference between two populations proportions. A one tail analysis was used in converting $z$. values into $P$. In part $A$, treated groups are compared to the day $3 \mathrm{Tx}$ group, while in part B, the anti-CD3 treated animals are compared to the animals treated with control hamster IgG

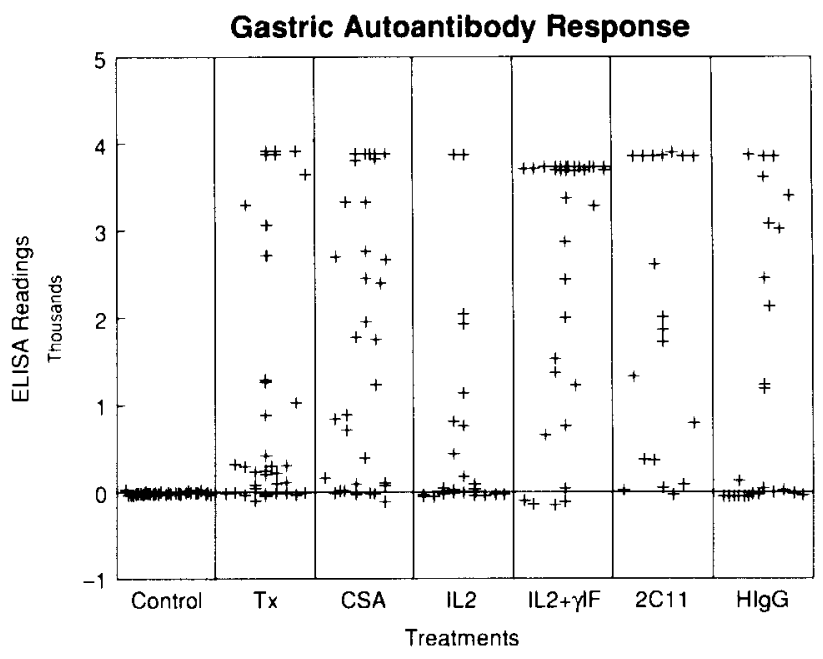

Figure $1 \mathrm{C} 3 \mathrm{H} / \mathrm{HeN}$ mice were thymectomized on day 3 or 4 and given different immune modulating treatments. Sera were obtained from mice at $20 \mathrm{wk}$ of age except for the group which received IL-2 and IFN $\gamma(12 \mathrm{wk})$. The ELISA readings were performed in duplicate. Each cross represents the average reading of an individual animal at a $1 / 80$ dilution of serum; the values obtained with the reference standard have been subtracted from each reading. Average readings of 200 or above were scored positive. 
post-Tx, the incidence of autoantibody production increased to $77 \%$ (Table 1; Figure 1).

\section{Inhibition of antigastric antibody production by administration of $I L-2$}

In order to examine the effects of IL-2 on the induction of autoantibody production, day $3 \mathrm{Tx}$ mice were treated with IL-2 (300-600 U/g/day) for $7 \mathrm{~d}$ post-Tx. All animals were followed for approximately $20 \mathrm{wk}$ or longer. The incidence of antigastric antibodies was markedly reduced in the IL-2 treated animals when assayed at either 11 or $20 \mathrm{wk}$ post-Tx (Table 1; Figure 1).

\section{Enhancement of autoantibody production by administration of anti-CD3}

As the preceding studies suggested that autoantibody production could be inhibited by IL-2 administration in the immediate post-Tx period and enhanced by an immunosuppressive drug that may block IL-2 production, we next evaluated whether stimulation of IL2 production by the systemic administration of antiCD3 would also inhibit the generation of antigastric antibodies. Surprisingly, administration of the anti$\mathrm{CD} 3 \mathrm{mAb}(20 \mu \mathrm{g} / \mathrm{animal})$ increased the incidence of antigastric antibodies from $39 \%$ in animals receiving the control normal hamster $\operatorname{IgG}(20 \mu \mathrm{g} / \mathrm{animal})$ to $85 \%$ (Table 1). We tested the effect of administering multiple cytokines to see if the results of the anti-CD3 treatment could be explained by the release of several cytokines. The combined administration of a IL-2 with IFN- $\gamma(1700-3300 \mathrm{U} / \mathrm{g} / \mathrm{d})$ increased the incidence of antigastric antibodies from $50 \%$ to $84 \%$ (Table 1). The administration of IFN $\gamma$ (1700$3000 \mathrm{U} / \mathrm{g} / \mathrm{d}$ ) for $4 \mathrm{~d}$ post $\mathrm{Tx}$ did not increase the incidence of antigastric antibodies in a group of 14 mice (data not shown).

\section{Effects of IL-2 on autoantibody production in NOD mice}

In order to extend our studies on the beneficial effects of IL-2 in reducing the incidence of autoantibody production to a different experimental model of autoimmunity, we studied the effects of $T x$ on the induction of antigastric antibodies in NOD mice. Although it has previously been reported that, in addition to diabetes, NOD mice develop autoimmune responses to other organs including the thyroid gland and stom$\mathrm{ach}^{8,9}$, the frequency $(3 \%)$ of antigastric antibodies was very low in euthymic NOD mice (Table 2; Figure 2 ); however, following day $3 \mathrm{Tx}$, the incidence of antigastric antibodies increased to $32 \%$ at $12 \mathrm{wk}$ which was less than that seen in thymectomized $\mathrm{C} 3 \mathrm{H}$ mice $(44 \%)$. We were unable to study the incidence of antigastric antibodies in the NOD mice after $12 \mathrm{wk}$ because a significant percentage of the mice had developed diabetes and many of the animals had died. The incidence of antigastric autoantibodies was similar in male and female in the thymectomized NOD mice and in $\mathrm{C} 3 \mathrm{H}$ mice (data not shown). The post-Tx administration of IL-2 decreased the incidence of antigastric antibodies in thymectomized NOD mice from $32 \%$ to $12 \%$ (Table 2; Figure 2).

\section{Effects of IL-2 on the development of diabetes in NOD} mice

In order to determine whether the beneficial effects of IL-2 administration could also be observed on the incidence of diabetes in NOD mice, we treated both euthymic and day $3 \mathrm{Tx}$ animals with IL-2 and monitored their blood glucose levels The prevalence of diabetes in euthymic NOD mice maintained in our colony varied greatly depending on sex $(0 / 18$ males compared to $15 / 21$ females, $71 \%$ ). This sex difference was much less apparent in the Tx NOD mice where $43 \%$ of males and $84 \%$ of females (Table 3 ) developed diabetes. Although the administration of IL-2 during the

Table 2 Effect of immune manipulation on the production of antibodies to gastric antigen in NOD mice.

\begin{tabular}{lccc}
\hline Treatment & + /Total & $\%$ & $P$ value \\
\hline Sham Tx & $1 / 34$ & $3 \%$ & \\
Day 3 Tx & $12 / 38$ & $32 \%$ & \\
Day 3 Tx+IL-2 & $4 / 33$ & $12 \%$ & 0.0222 \\
\hline
\end{tabular}

NOD mice were thymectomized or sham thymectomized around day 3 of life. Antigastric antigen titers were performed at $12 \mathrm{wk}$ of age. $\mathrm{P}$ values were calculated as in the legend to antigen titers were performed at $12 \mathrm{wk}$ of age. $\mathrm{P}$ values were calculat
Table 1 . The day $3 \mathrm{Tx}+\mathrm{IL}-2$ group is compared to the day $3 \mathrm{Tx}$ group.

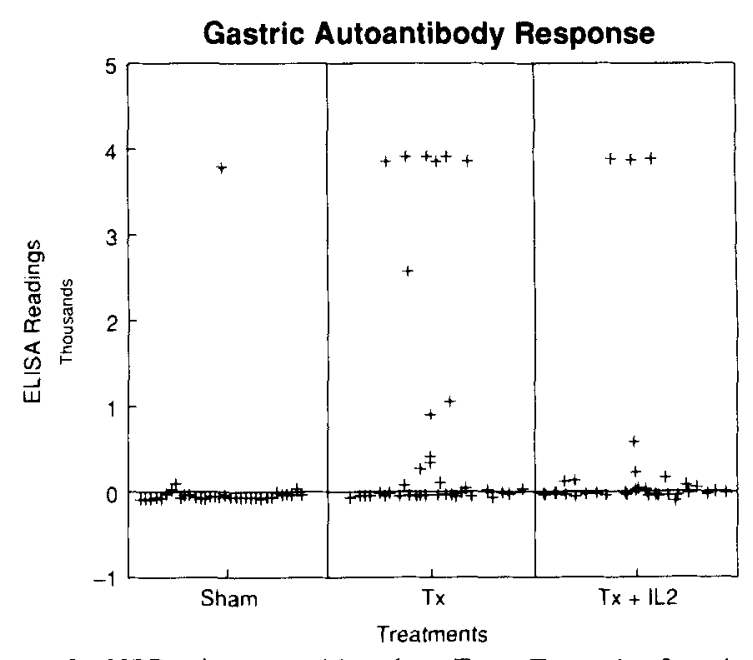

Figure 2 NOD mice were either sham Tx or Tx on day 3 or 4 of life. One group of thymectomized animals was treated with human recombinant IL-2. Sera were prepared from mice approximately 12 wk old and the ELISA readings were performed as described in the legend to Figure 1. 
Table 3 Effect of immune manipulation on the incidence of hyperglycemia in NOD mice

\begin{tabular}{llrr}
\hline Treatment & Sex & +/Total & \multicolumn{1}{c}{$\%$} \\
\hline PBS & Females & $15 / 21$ & $71 \%$ \\
& Males & $0 / 18$ & $0 \%$ \\
IL-2 & Females & $11 / 16$ & $69 \%$ \\
& Males & $1 / 23$ & $4 \%$ \\
Sham Tx & Females & $9 / 16$ & $56 \%$ \\
& Males & $0 / 18$ & $0 \%$ \\
Tx & Females & $16 / 19$ & $84 \%$ \\
& Males & $9 / 21$ & $43 \%$ \\
Tx+lL-2 & Females & $16 / 21$ & $76 \%$ \\
& Males & $5 / 13$ & $38 \%$
\end{tabular}

NOD mice in the first two groups received either PBS or IL-2 treatment for $7 \mathrm{~d}$ starting on day three of life. Tx or sham $T x$ were performed on the last three groups with the fifth group receiving both $T x$ and a $7 \mathrm{~d}$ course of IL-2 post Tx. Animals were bled and tested $f_{0}$ hyperglycemia using a chemsirip. Blood glucose levels over $300 \mathrm{mg} / \mathrm{dl}$ were regarded as posil ive. The experiment was stopped when the animals reached 6 months of age.

\section{Effect of IL2 on Development of Diabetes}

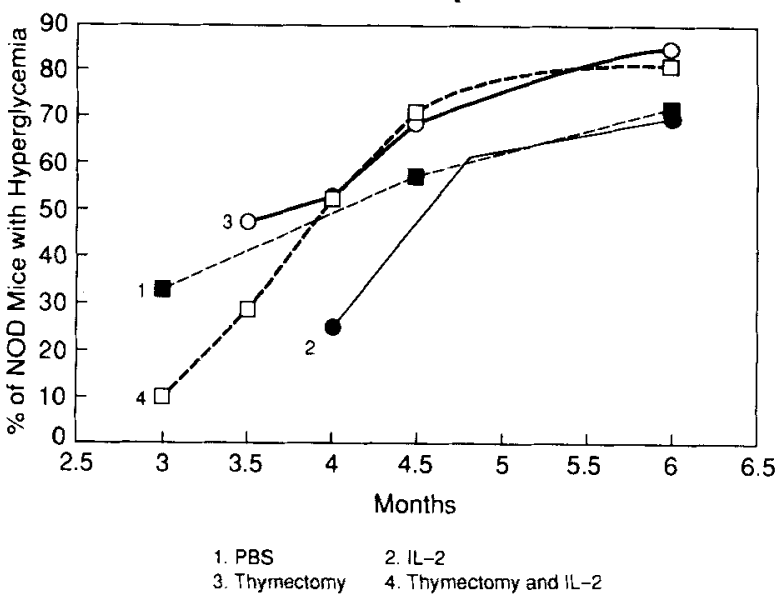

Figure 3 Effect of IL-2 on the development of hyperglycemia Euthymic female, NOD mice were given PBS (group 1) or IL-2 (Group 2) for $7 \mathrm{~d}$ starting on the fourth day of life; alternatively, female NOD mice were thymectomized on day 3 or 4 of life and injected with PBS (group 3) or IL-2 (group 4) for $7 \mathrm{~d}$ post surgery. Blood glucose levels were determined using a glucose sensitive chemstrip. Levels above $300 \mathrm{mg} / \mathrm{dl}$ were scored positive.

first week of life was able to modestly suppress the onset of diabetes during the first few months of life, at 4-6 months of age, no difference in the incidence of hyperglycemia was observed between the IL-2 treated and the control animals (Table 3; Figure 3).

\section{DISCUSSION}

The goal of the present studies was to determine whether the administration of immunomodulatory cytokines or drugs in the immediate post-Tx period would influence the development of autoantibodies in animals thymectomized on day 3 of life. We monitored antigastric antibodies because they are easy to assay and because about $50 \%$ of our $\mathrm{C} 3 \mathrm{H}$ mice developed these autoantibodies; thus, they provided a good system for determining if the frequency of disease increased or decreased ${ }^{1.10}$. These autoantibodies may have clinical significance because the human equivalent react with the $\mathrm{H} / \mathrm{K}$-ATPase pump in parietal cells and are used to diagnose autoimmune gastritis in man". We attempted to monitor autoantibodies to thyroid, ovary, DNA, RNA, and histones, but these antibodies were too rare to be used as indicators. Histopathology was also too rarely observed in $\mathrm{C} 3 \mathrm{H}$ mice to use as an indicator of immune modulation.

Our experiments demonstrated that post-Tx administration of CsA was able to significantly increase the incidence of animals which produced antigastric antibodies in day 3 thymectomized mice. The addition of IL-2 in the immediate post $T x$ period decreased the incidence of antigastric antibody production in both $\mathrm{C} 3 \mathrm{H} / \mathrm{HeN}$ and NOD mice. In contrast, the combined administration of IL-2 and gamma interferon during this same period increased the development of antigastric antibodies. To our knowledge these results are the first to provide strong evidence that transient lymphokine changes in the extrathymic immune system during the first week of life have a major effect in determining if an animal develops antigastric antibodies.

We also examined the effects IL-2 administration on the development of hyperglycemia in the NOD mouse which develops insulitis by $3-5 \mathrm{wk}$ and diabetes within 3-6 months of age. There is strong evidence that diabetes in the NOD strain is caused by an autoimmune response to the pancreatic islet cells because the disease can be transferred by $T$ cells, the animals develop islet cell antibodies, lymphocytic infiltrates can be seen around the $\beta$ cells, and the disease can be modulated by immunosuppressants or other immune modulators. Although $\mathrm{Tx}$ on day 0 inhibited the development of the disease ${ }^{12}$, we observed that day 3 Tx markedly enhanced the incidence of the disease particularly in male mice. We believe these findings are the first to show that day 3 $\mathrm{Tx}$ enhances the development of diabetes. While the effect of IL-2 in diminishing the frequency of antigastric antibodies in day 3 Tx NOD mice was substantial, IL-2 produced only a modest and transient diminution in the frequency of animals that developed hyperglycemia. It is therefore possible that these two models of autoimmune disease may involve distinct pathogenetic mechanisms.

Our results on the failure of IL-2 to prevent diabetes in NOD mice agree with those of Satoh et al. ${ }^{13}$, but differ from those of Serreze et al. ${ }^{14}$ who demonstrated a highly therapeutic effect of IL-2 in NOD mice. The differences between these studies may be secondary to the concentration of IL-2 administered, the time of administration, the diet used to feed the 
animals, or to the substrain of NOD mouse used. In the studies of Serreze et $a l^{14}$ the incidence of diabetes in males was $50 \%-70 \%$ compared to the NOD mice in our studies where the incidence in males is around $5 \%$.

Several mechanisms have been proposed to explain the induction of autoimmune disease following day 3 Tx. Smith et al. ${ }^{15}$ have demonstrated that mice thymectomized soon after birth contain in their peripheral lymphoid tissues $T$ cells with receptors that are normally deleted in the thymus. Although it is possible that these $\mathrm{T}$ cells with potentially autoreactive receptors are responsible for the induction of organ specific autoimmunity, Jones, et al. ${ }^{16}$ have shown that such potentially autoreactive cells are non-functional as measured by their inability to proliferate and produce cytokines following stimulation with anti-TCR mAbs. Furthermore, T cells with potentially autoreactive receptors have been observed in day $3 \mathrm{Tx}$ mice from strains which do not develop autoimmune diseases. An alternative possibility is that Tx may also be inducing autoimmunity by the removal of cells that can make IL-2. Although it has been proposed that the induction of autoimmunity following the administration of CsA may be secondary to the failure to clonally delete autoreactive $T$ cells ${ }^{17}$ or to aberrant development of suppressor cells ${ }^{3}$, it is also possible that CsA may induce autoimmunity by inhibiting the production of IL-2 in vivo.

Taken together our studies suggest that the presence of IL-2 early in life can reduce the development of certain autoantibodies later in life. We hypothesize that both the CsA and the day $3 \mathrm{Tx}$ may be inducing autoantibodies by inhibiting the production of IL-2 early in life. Although we have not determined the cellular site of action of IL-2, we favor the view that IL-2 plays a major role in the thymic independent induction of non-responsiveness or anergy to selfantigens in the periphery. Schell and Fitch ${ }^{18}$ have shown that a large pulse of IL-2 can cause anergy in vitro. Lenardo ${ }^{19}$ has proposed that IL-2 plays a critical role in the clonal elimination of $\mathrm{T}$ cells extrathymically by inducing apoptosis after antigen receptor engagement. Thus, the elimination of $\mathrm{T}$ cells with autoreactive TCRs could be facilitated by IL- 2 treatment. Alternatively, we cannot rule out the possibility that IL-2 may induce the proliferation and expansion of a regulatory $T$ cell population which has been suggested to prevent disease ${ }^{20}$.

\section{References}

1. Kojima A, Prehn RT. Genetic susceptibility to post-thymec- tomy autoimmune diseases in mice. Immunogenetics 1981; 14: 15-27

2. Kojima A, Taguchi O, Nishizuka Y. Experimental production of possible autoimmune gastritis followed by macrocytic anemia in athymic nude mice. Laboratory Investigation 1980; 40: 387

3. Sakaguchi S, Sakaguchi N. Organ-specific autoimmune disease induced by elimination of $\mathrm{T}$ cell subsets. $J$ Immunology 1989; 142: $471-480$

4. Shevach EM. The effects of cyclosporin A on the immune system. Ann Rev Immunology 1985; 3: 397-423

5. Sjodin K, Dalmasso AP, Smith JM, Martinez C. Thymectomy in newborn mice. Transplantation 1963; 1: 521--525

6. Leo O. Foo M, Sachs DH, Samelson LE, Bluestone JA. Identification of a monoclonal antibody for a murine $\mathrm{T} 3$ polypeptide. Proc Natl Acad Sci USA 1987; 84: 1374-1378

7. Classen JB, Sevach EM. Evidence that cyclosporine treatment during pregnancy predisposes offspring to develop autoantibodies. Transplantation 1991; 51: 1052-1057

8. Pontesilli O, Carotenuto P, Gazda LS, Pratt PS, Prowse SJ. Circulating lymphocytic populations and autoantibodies in nonobese diabetic (NOD) mice: a longitudinal study. Clin Exp Immunology 1987; 70: 84-93

9. Bernard NF, Ertug F, Margolese H. High incidence of thyroiditis and antithyroid autoantibodies in NOD mice. Diabetes 1992; 41: 40-46

10. Fukuma K, Sakaguchi S, Kuribayashi K, Chen W, Morishita R. Sekita K, Uchino H, Masuda T. Immunological and clinical studies on murine experimental autoimmune gastritis induced by neonatal thymectomy. Gastroenterology 1988; 94: 274-283

11. Toh BK, Gleeson PA, Simpson RJ, Moritz RL, Callaghan JM, Goldkorn I, et al. The 60- to 90-kDa parietal cell autoantigen associated with autoimmune gastritis is a beta subunit of gastric H/K-ATPase (Proton Pump); Proc Natl Acad Sci USA 1990; 87: 6418-6422

12. Agawa M, Maruyama T, Hasegawa T, Kanaya T, Kobayashi F, Tochino $Y$, Uda $H$. The inhibitory effect of neonatal thymectomy on the prevalence of insulitis in mice. Biomed Res 1985; 6: $103-105$

13. Satoh J, Seino H, Abo T, Tanaka S, Tamura K. Ohta S, et al. Recombinant human tumor necrosis factor-alpha suppresses autoimmune diabetes in nonobese diabetic mice. J Clin Invest 1989; 84: $1345-1348$

14. Serreze DV, Hamguchi K, Leiter EH. Immunostimulation circumvents diabetes in NOD/Lt mice. $J$ Autoimmunity 1989; 2: 759-776

15. Smith H, Chen IM, Kubo R, Tung KSK. Neonatal thymectomy results in a repertoire enriched in $\mathrm{T}$ cell deleted in adult thymus. Science 1989; 245: 749-752

16. Jones LA, Chin LT, Merriam GR, Nelson LM, Kruisbeck AM. Failure of clonal deletion in neonatally thymectomized mice: tolerance is preserved through clonal anergy. J Exp Med 1990; 172: $1277-1285$

17. Jenkins MK, Schwartz RH, Pardoll DM. Effects of cyclosporine A on T cell development and clonal deletion. Science 1988; 241: $1655-1658$

18. Schell SR, Fitch FW. Pretreatment of cloned helper lymphokines with IL-2 induces unresponsiveness to antigen and concanavalin $\mathrm{A}$, associated with decreased inositol phosphate and diacylglycerol production. $J$ Immunology 1989; 143: 1499-1505

19. Lenardo MJ. Interleukin-2 programs mouse alpha beta T lymphocytes for apoptosis. Nature 1991 ; 353: 858-861

20. Elson CO. Do organ specific suppressor cell $\mathrm{T}$ cells prevent autoimmune gastritis? Gastroenterology 1990; 98: 226-228 